\title{
Ultrasonographic Assessment of Embryonic Loss between Days 28 And 45 Post Insemination in Crossbred Dairy Cattle of Kerala
}

\author{
E. Niyas ${ }^{1 *}$, Shibu Simon ${ }^{1}$, Reni John", Ani S. Das ${ }^{2}$, D. S. Suprith ${ }^{2}$, \\ S. Reshma ${ }^{2}$ and Anugraha Mercy Easaw ${ }^{2}$ \\ ${ }^{1}$ ULF\&FRDS, College of Veterinary and Animal Sciences, Mannuthy, Thrissur, \\ Kerala, India, 680651 \\ ${ }^{2}$ College of Veterinary and Animal Sciences, Mannuthy, Thrissur, Kerala, India, 680651 \\ *Corresponding author
}

\section{A B S T R A C T}

\begin{tabular}{|l|}
\hline Ke y w o r d s \\
$\begin{array}{l}\text { Embryonic loss, } \\
\text { ultrasonography, } \\
\text { crossbred cattle, } \\
\text { inter-calving } \\
\text { interval }\end{array}$ \\
\hline Article Info \\
\hline $\begin{array}{l}\text { Accepted: } \\
\text { 05 April } 2020 \\
\text { Available Online: } \\
\text { 10 May } 2020\end{array}$ \\
\hline
\end{tabular}

Embryonic mortality (EM) is a major concern in the dairy industry across the world and it occurs due to loss of conceptus following fertilization until days 42-45 of pregnancy. The present study was carried out with the objective to detect EM in the crossbred cattle at the University Livestock Farm, Mannuthy, Kerala Veterinary and Animal Sciences University during the period from September 2017 to August 2019. Among the breedable animals inseminated at spontaneous oestrus, non-return animals $(n=362)$ were selected for the study. Transrectal ultrasonography (TRUS) using a $7.5 \mathrm{MHz}$ transducer was performed on days 28 and 45, respectively to diagnose pregnancy and to detect embryonic mortality if any. Out of 362 animals which exhibited non-return to oestrus, 73.76 per cent $(n=267)$ were found positive for pregnancy on day 28 and out of these, 95.88 per cent animals $(n=256)$ were having viable embryo with detectable heart beat on day 45.Thus, the incidence of EM in the current investigation was 4.12 per cent between days 28 and 45 post- service. In conclusion, use of ultrasonography to detect embryonic loss and pathological conditions, at the early stages of gestation helps to reduce the inter-calving interval, a key factor of successful dairying.

\section{Introduction}

Embryonic mortality is the prime cause of economic loss in dairy industry and is generally defined as the loss of conceptus that occurs during the first 45 days of pregnancy, the period from conception to completion of organogenesis. Direct effects of EM are reflected in reduced conception rates with consequent effects on reproductive efficiency, production and profitability. Approximately 30 per cent of pregnancies are lost in the form of embryonic death causing an increase in the successive calving interval, thereby ultimately affecting the success of reproductive programs in dairy cows (Chaudhary and Purohit, 2012). Majority of embryonic losses occur before 16 days of breeding although 
there are reports on greater incidence of losses before day 8 in high producing dairy cows. Early embryonic mortality leads to repeat breeding, increased cost of artificial insemination and treatment, extended calving intervals and prolonged dry period resulting in reduced milk production and net calf crop (Bajaj, 2001).

Late embryonic mortality causes serious economic losses since it is often recognized extremely late to rebreed females. About 80 per cent of the embryonic loss occurs before days $16-17 ; 10$ - 15 per cent between days 17 - 42 and 5 per cent after day 42. Earlier, it was believed that the bovine conceptus gets reabsorbed after early embryonic death, but transrectal ultrasound examination has demonstrated that the conceptus and its breakdown products apparently are eliminated by expulsion through the cervix, which either goes unnoticed or appear as a vulvar discharge of clear mucus (Kastelic et al., 1991).

Mainly infectious and hormonal factors may participate in embryonic mortalities (Bajaj and Sharma, 2011). Among the infectious factors, viral, bacterial, protozoal and mycoplasmal infections result in embryonic death, indirectly by systemic effects via septicemia, viremia or toxemia in the dam or directly affecting the embryo or contaminating the uterine environment. Embryonic mortality caused by systemic pathogens is usually depicted by fever or pyrexia during the infection. Elevated body temperature present in the first stage of pregnancy can lead to early embryonic death as a result of denaturation of embryonic proteins. Luteal insufficiency during post insemination period is considered as one of the predisposing factors leading to EM (Diskin and Moris, 2008). Embryonic mortality can be diagnosed by using a variety of techniques including measurement of milk progesterone concentration (Stronge et al., $2005)$ or pregnancy specific proteins (Prvanovic et al., 2009), transrectal ultrasonography (Romano et al., 2006) and transrectal palpation (Balhara et al., 2013; Bekele et al., 2016).

Ultrasound has previously been reported to be an economically profitable reproductive management strategy for dairy farms (Beal et al., 1992) and under Indian scenario the incidence of early embryonic mortality has not been studied in detail so far. With the advent of real time ultrasound in modern times, the foresaid can be utilised in organized farms to detect early pregnancy and embryonic mortalities. Hence the present study was carried out with the objective to detect EM in the crossbred cattle from day 28 to 45 post-insemination.

\section{Materials and Methods}

The present study was carried out with the objective of utilizing real time B-mode TRUS in the detection of embryonic loss in a herd of crossbred cows which are maintained under identical feeding and management conditions at the University Livestock Farm, Mannuthy, Kerala Veterinary and Animal Sciences University. The study was undertaken during September 2017 to August 2019. Animals selected for experiments were free from any kind of anatomical and reproductive disorders, were clinically healthy and had a body condition score (BCS) of over 2.5 on a scale from 1 to 5 (Edmonson et al., 1989).

The age group and body weight of the animals ranged between 2 to11years and 300 to $450 \mathrm{~kg}$, respectively. All the breedable animals detected at spontaneous oestrus were subjected to artificial insemination according to $\mathrm{AM} / \mathrm{PM}$ rule and were inseminated with elite quality frozen semen after proper thawing. 
Re-insemination after $24 \mathrm{~h}$ was carried out in those cows in which oestrous signs persisted. TRUS was done with a real time colour Doppler ultrasound scanner Mylab $^{\mathrm{TM}}$ Gamma, EsoateSpA, Italy) equipped with liner array, 5-10 $\mathrm{MHz}$ frequency transrectal transducer (SV3513, Esaote Europe B.V, Netherland).The gain, brightness and contrast were set optimally for each examination.

\section{Early pregnancy diagnosis at day 28 post AI}

Among all the inseminated animals, those exhibited non-return to oestrus $(n=362)$ were subjected to transrectal real time B-mode and Doppler ultrasonography. A real time B-mode ultrasound scanner equipped with a linear array transrectal multi-frequency transducer using frequency of $7.5 \mathrm{MHz}$ was used to diagnose pregnancy at day 28 postinsemination. After proper restraining of the animal the faecal material was removed from the rectum. The transducer and the sleeved arm of the examiner were lubricated with ultrasound gel to facilitate smooth insertion through the anal sphincter and to establish good contact with the floor of the rectal mucosa. The transducer was safeguarded within the hand before its insertion into the rectum. The transducer was positioned dorsal to the genital tract and slowly advanced cranially. Initially the corpus luteum was located by scanning both the ovaries with controlled method of holding the probes, without manipulating the ovarian position. After initial orientation of the CL, ipsilateral uterine horn was scanned over its dorsal surface followed by the lateral surface for detecting embryonic vesicle or embryo. A presumptive diagnosis of pregnancy was made if an anechoic fluid area was seen in the uterine lumen. Further examination was carried out to visualise embryo within the uterine lumen, and if observed, it confirmed the diagnosis of pregnancy. Embryonic heart beats were used as the main criteria to assess the viability of the embryo and the heart beat was observed within the cranial, cone-shaped thorax of the embryo.

\section{Re-examination at day 45 post $\mathrm{AI}$}

Animals which were diagnosed as pregnant at day 28 by the presence of viable embryo were subjected to a transrectal sonographic reexamination, for detecting embryonic loss, if any. Such embryonic mortality was assessed on the basis of observing changes in the echogenicity of the uterine contents and/or loss of amniotic and allantoic fluid from the uterus.

\section{Results and Discussion}

\section{Early pregnancy diagnosis at day 28 post AI}

Among all the inseminated animals, those exhibited non-return to oestrus $(n=362)$ were subjected to TRUS. The uterus was located well and was visualized through all sides with the transducer in all the animals. Thus, the chances of missing the embryonic vesicle were negligible. Functional corpus luteum (CL) was detected using B-mode ultrasonography and its blood flow was assessed by the Doppler system (Fig 1).

Positive diagnosis of pregnancy was based on the presence of a functional CL with active blood flow and anechoic round area of varying size in the lumen of uterine horn representing the fluid filled allantoic cavity. In the anechoic vesicle, echogenic embryo with heartbeat was identified (Fig 2 and Fig 3 ). The embryonic heart beats were used as the main criteria to assess the viability of the embryo and the heart beat was observed within the cranial, cone-shaped thorax of the embryo and the blood flow to heart was assessed by using Doppler system. 
Out of 362 non- return animals 267 animals $(73.76 \%)$ were found positive for pregnancy on day 28. Among the non-return cows 16.85 per cent $(n=61 / 362)$ had shown prolonged interoestrus interval ( $>24$ days as against the normal cycle length of 18-24 days), which could be attributed to EED.

\section{Re-examination for pregnancy on day 45 post AI}

Animals which were diagnosed as pregnant at day 28 by the presence of viable embryo were subjected to a transrectal sonographic reexamination at day 45 for detecting embryonic viability. Pregnancy was confirmed based on the detection echogenic embryo within the amniotic cavity surrounded by increased amount of anechoic amniotic and allantoic fluid. Out of 267 pregnant animals, 95.88 per cent animals $(n=256)$ had viable embryo with heart beat on day 45 (Fig. 4 and 5) and 11 animals exhibited an embryonic loss between days 28 and 45 post AI. Thus, the incidence of embryonic mortality in the current investigation was 4.12 per cent between days 28 and 45 .

\section{Embryo resorption/ expulsion}

In majority of the animals $(n=10 / 11)$ which exhibited embryonic loss between day 28 and 45 post AI the process of fetal resorption or expulsion was completed before day 45 . Transrectal ultrasonographic re-examination on day 45 revealed absence of embryonic debris, fetal membranes and uterine fluids and those animals returned to oestrus after day 45 . One animal exhibited oestrus signs on day 42 post-AI, wherein Doppler ultrasonography revealed reduced blood supply to the corpus luteum verum (Fig 6) and the volume of allantoic and amniotic fluid was greatly reduced. No viable embryo was visible inside the amniotic vesicle and an abnormal thickening of fetal membranes could be noticed (Fig 7). Vaginal discharge was noticed for a few days, along with cessation of the luteal blood flow (Fig 8), disappearance of embryo debris and fetal membrane observed by day 49 (Fig 9) and the uterus returned to normal non gravid state by day 52 (Fig 10).

\section{Discussion}

The prime considerations to reduce the intercalving interval in dairy animals are early diagnosis of pregnancy, identifying uterine or ovarian pathological conditions and early detection of those animals that fail to conceive after service (Pieterse et al., 1990). Ultrasonography has an advantage over traditional method of rectal palpation in pregnancy diagnosis, detection of fetal viability and assessment of embryonic loss during early stages of gestation (Kastelic et al., 1988 and Patel et al., 2005). The introduction of ultrasonography for early pregnancy diagnosis has allowed researchers to differentiate the timing and extent of late embryonic losses in cattle (Santos et al., 2004).

\section{Early pregnancy diagnosis at day 28 post AI}

In the present study the pregnancy was diagnosed as early as day 28 post-AI wherein positive diagnoses of pregnancy by transrectal ultrasonography relied on the detection of anechoic allantoic fluid and the embryo proper. The study conducted by Romano et al., 2006) agree with the fact that, TRUS can be used for early pregnancy diagnosis in bovines with a maximum sensitivity between days 28 and 30 post-service. TRUS has maximum sensitivity for pregnancy diagnosis in cattle, TRUS for pregnancy diagnosis between days 26 and 33 after breeding has a sensitivity and specificity of 97.7 per cent and 87.7 per cent respectively (Pieterse et al., 1990). 
Contrarily, sonographic detection of pregnancy in cattle on days $23,28,35$ post-AI is less accurate than on day 42 and TRUS can be perform with maximum sensitivity and specificity between days 35- 42 in Zebu cattle (Hadiya et al., 2015; Awasthi et al., 2011 and Bhoraniya et al., 2011)

In the present study, among the non-return cows 16.85 per cent $(n=61 / 362)$ animals had shown prolonged interoestrus interval (>24 days as against the normal cycle length of 1824 days) which could be attributed to early embryonic death (EED) that occurred after the MRP.

Similar observations were reported by Noakes et al., (2009), in which the animal will return to normal oestrus if the embryonic death occurs before the maternal recognition of pregnancy (MRP), 17 days in case of bovines. If the embryonic loss occurs after the MRP, the animal will exhibit a prolonged interoestrus interval.

\section{Embryonic loss between days 28 and 45 post AI}

In this particular study an embryonic loss of 4.12 per cent was observed between days 28 and 45 of AI among crossbred cattle of Kerala. This result is in agreement with the findings of Rani et al., (2018), who conducted their study in a herd of Sahiwal and Hardhenu cows in Hariyana and reported an incidence of 3.77 per cent $(n=2 / 53)$ embryonic loss between day 28 and 45 post- service and Silke et al., (2002) who used TRUS and recorded the embryonic losses in cows and heifers between days 28-42, 43-56, 57-70 and 71-84 to be 3.2 and $1.52,1.99$ and $2.27,0.66$ and 1.51 and 1.34 and 0.76 per cent respectively.

Whereas a higher rate $(12.8 \%)$ of pregnancy loss between day 30 and day 45 of gestation was noticed in dairy cows, which is higher than that observed for beef cows (Beal et al., 1992).

\section{Embryo resorption/ expulsion}

Embryonic death usually followed by either resorption or expulsion of the embryo and uterine contents. In our study, majority of the animals which exhibited embryonic loss between days 28 and 45 post- service did not shown any evidence of embryo expulsion.

One animal showed clear vaginal discharge during the time of embryonic death and the uterine contents were expelled through the tract. This finding is in accordance with the reports of Kastelic et al., (1991), wherein they opined that TRUS examination has demonstrated the embryo and its breakdown products being apparently eliminated by expulsion through the cervix, which either goes unnoticed or appear as a vulvar discharge of clear mucus.

The extent of late embryonic loss is less compared to early embryonic loss and causes serious economic losses, particularly in seasonal calving herds, since it is often too late to rebreed cows, which results in increased culling rates and replacement cost (Grimard et al., 2006).

Late embryonic mortality can be diagnosed when the embryo is detected without a heartbeat or when a previously observed embryo with a heartbeat is no longer visible during subsequent ultrasonographic examinations (Szenci et al., 1998; Rani et al., 2018). Subsequent pregnancy examinations to identify and rebreed cows that experience early embryonic losses are of utmost importance since the reproductive efficiency is remarkably reduced among these animals by extending the calving interval (Frick, 2002). 


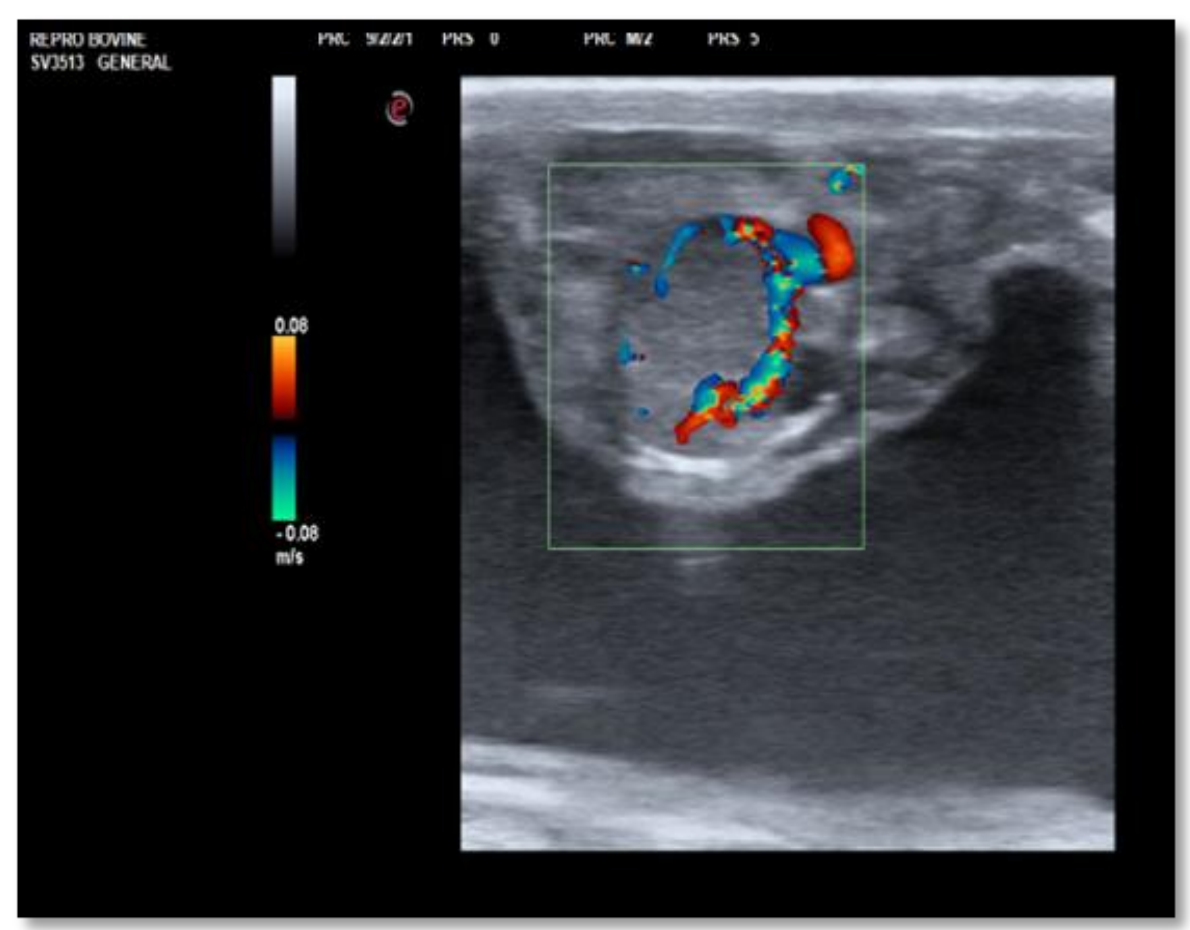

Fig.1 Doppler ultrasonographic image of the right ovary of a cow with a functional corpus luteum showing active blood flow towards the periphery of the CL at day 28 post AI

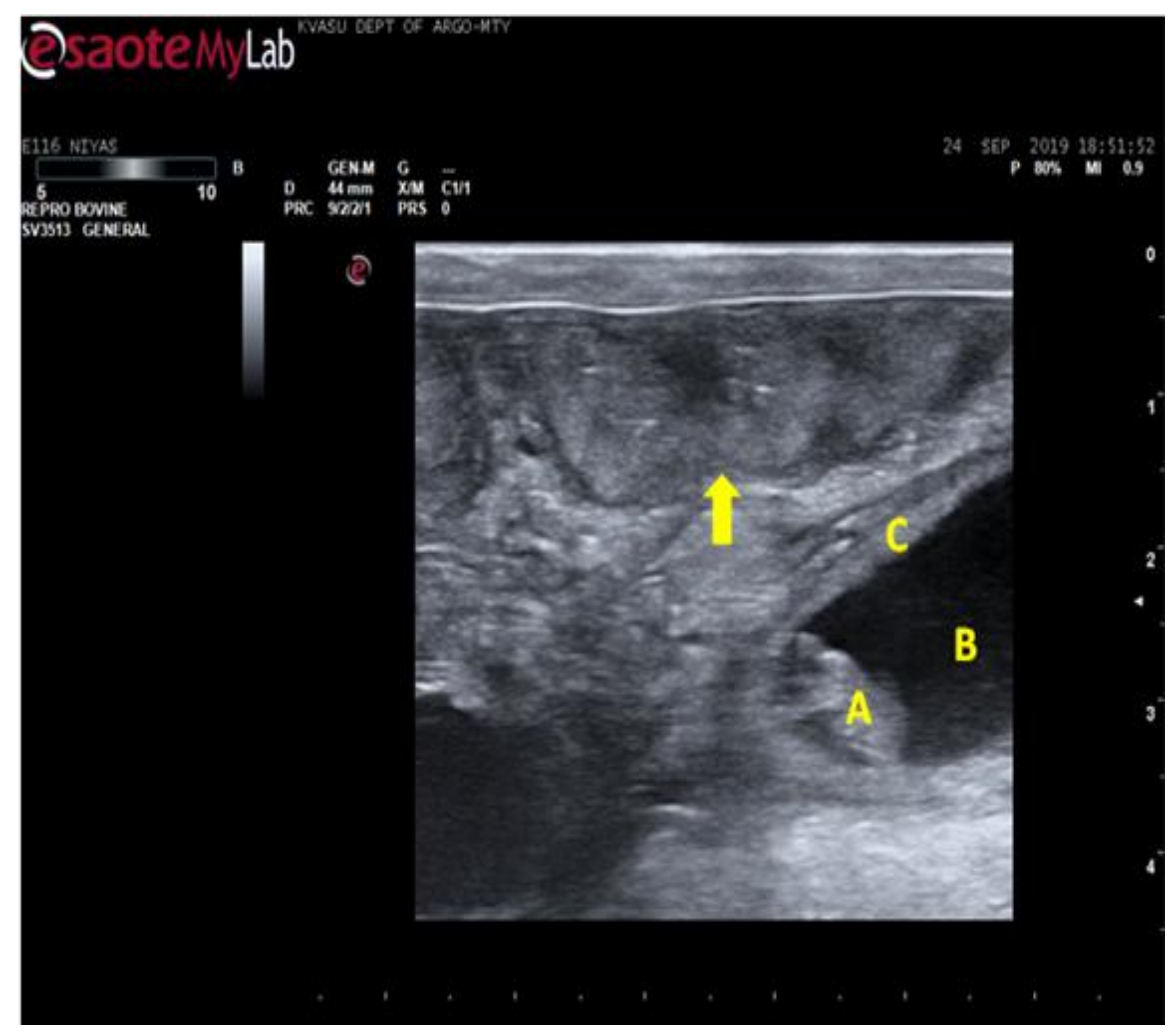

Fig.2 An embryo is located on the uterine horn ipsilateral to the corpus luteum bearing ovary at day 28 post AI (7.5 MHz probe; depth $4.4 \mathrm{~cm}$ );A- Embryo, B- Allantoic fluid, C- Gravid horn, Arrowhead- Non gravid horn 


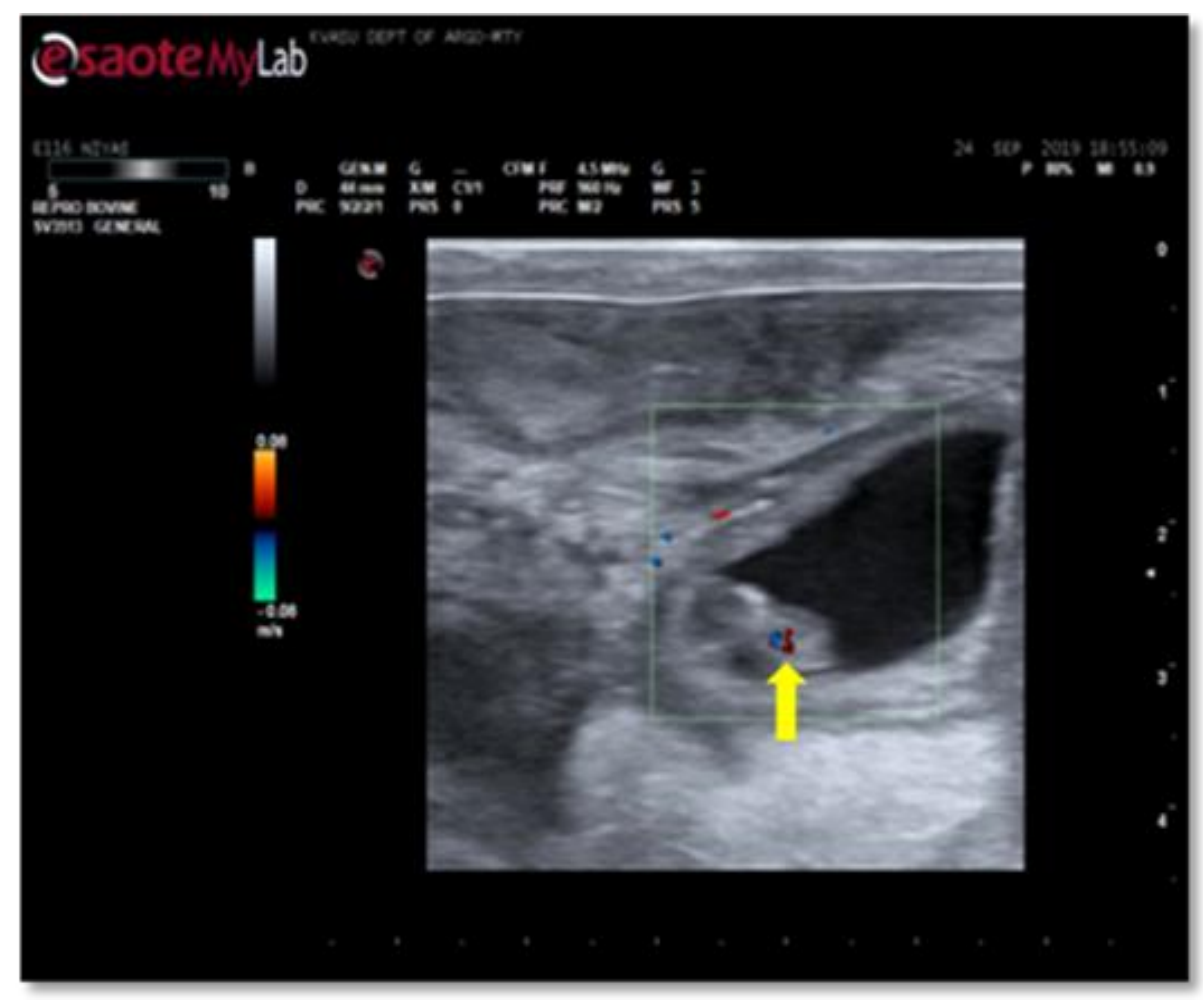

Fig.3 Doppler sonographic assessment of embryo viability by detecting blood flow at the cardiac region

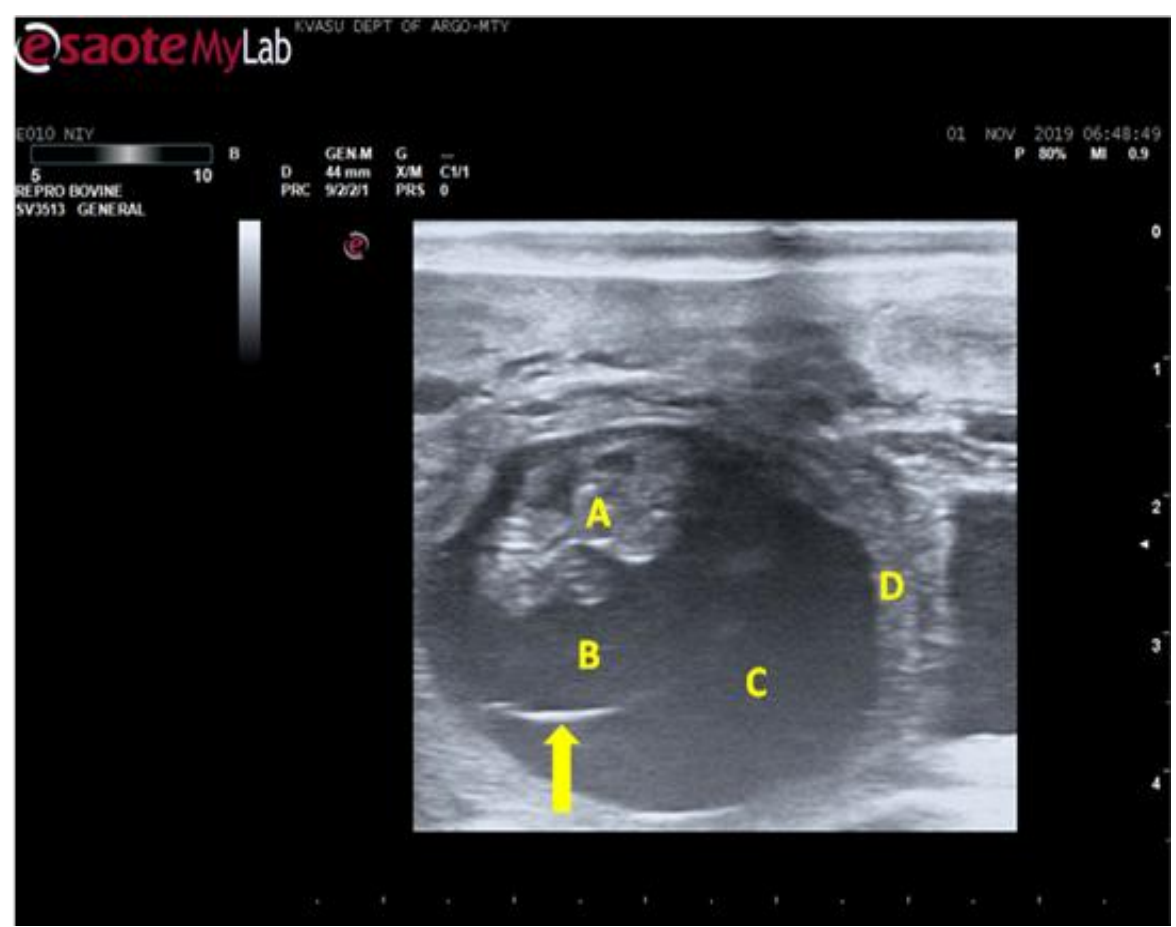

Fig.4 Ultrasonographic image of 45 day old embryo (7.5 MHz probe; depth $4.4 \mathrm{~cm}$ ), A: Embryo; B: Amniotic fluid; C: Allantoic fluid; D: Uterine wall; Arrow Head: Amniotic membrane in pregnant horn of cow on day 45 


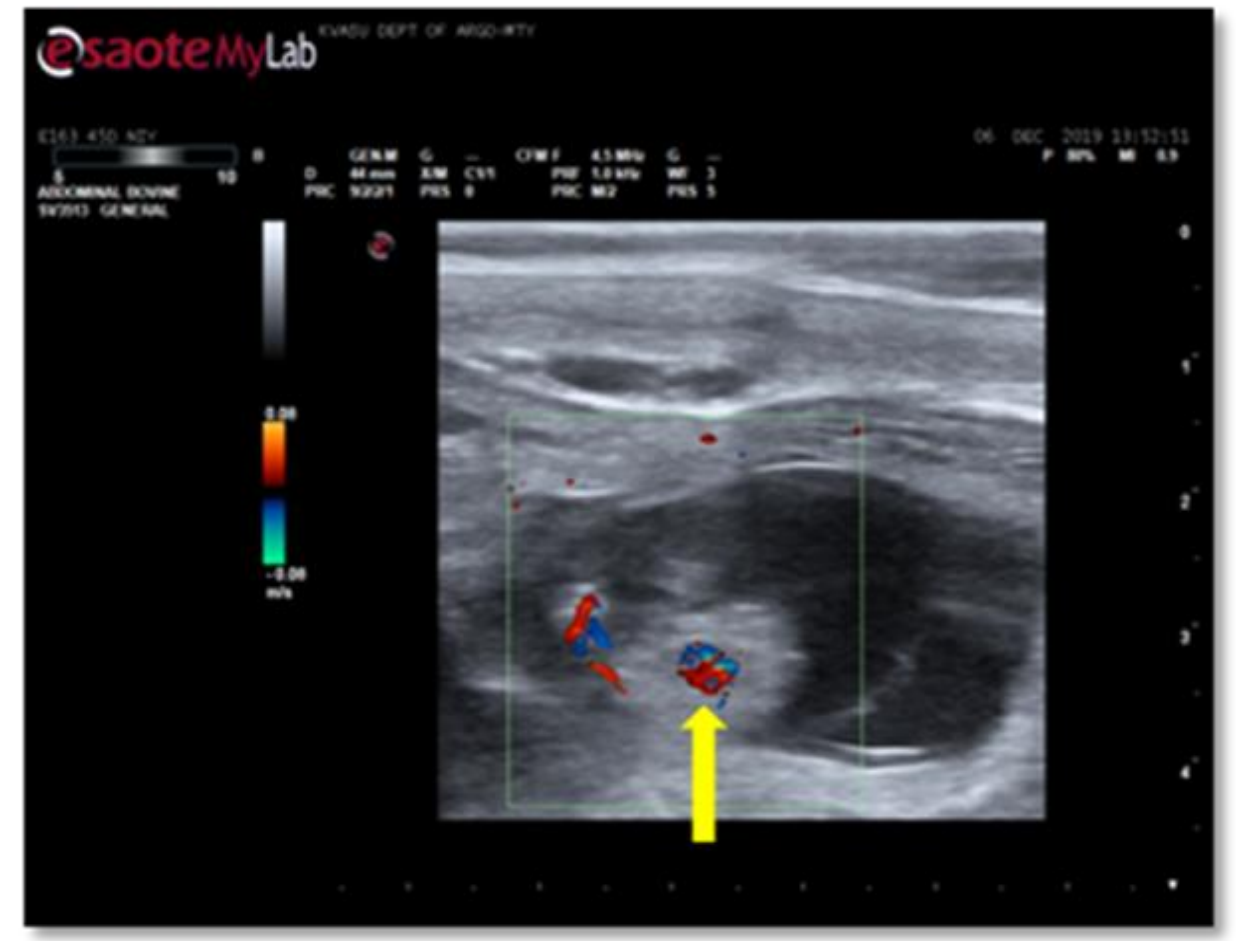

Fig.5 Doppler ultrasonographic image of viable embryo at day 45, Arrow head: blood flow detected using Doppler ultrasonography at the cardiac region of embryo

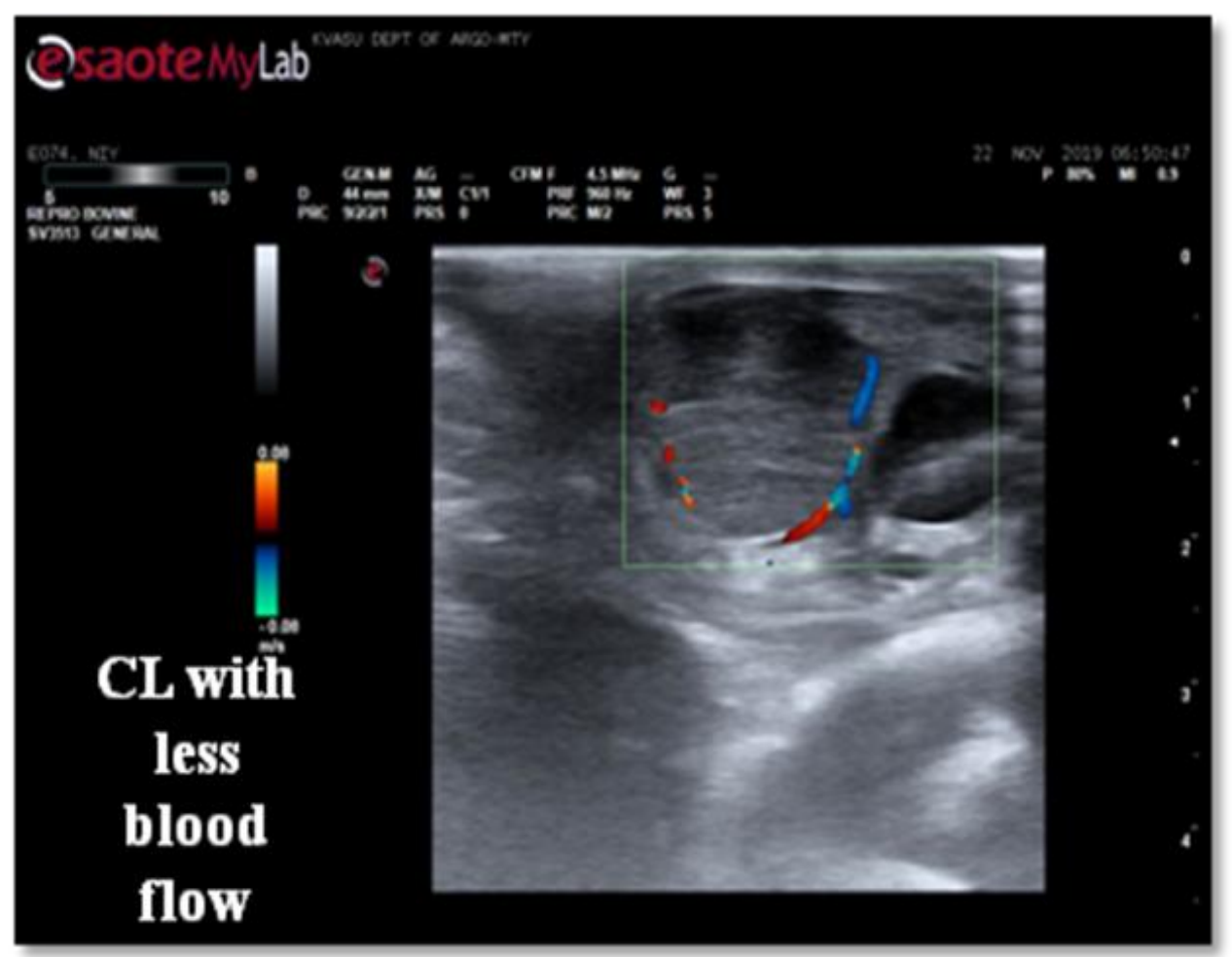

Fig.6 Doppler ultrasonographic image of corpus luteum verum showing reduced perfusion indicating onset of luteal regression or weak $\mathrm{CL}$ 


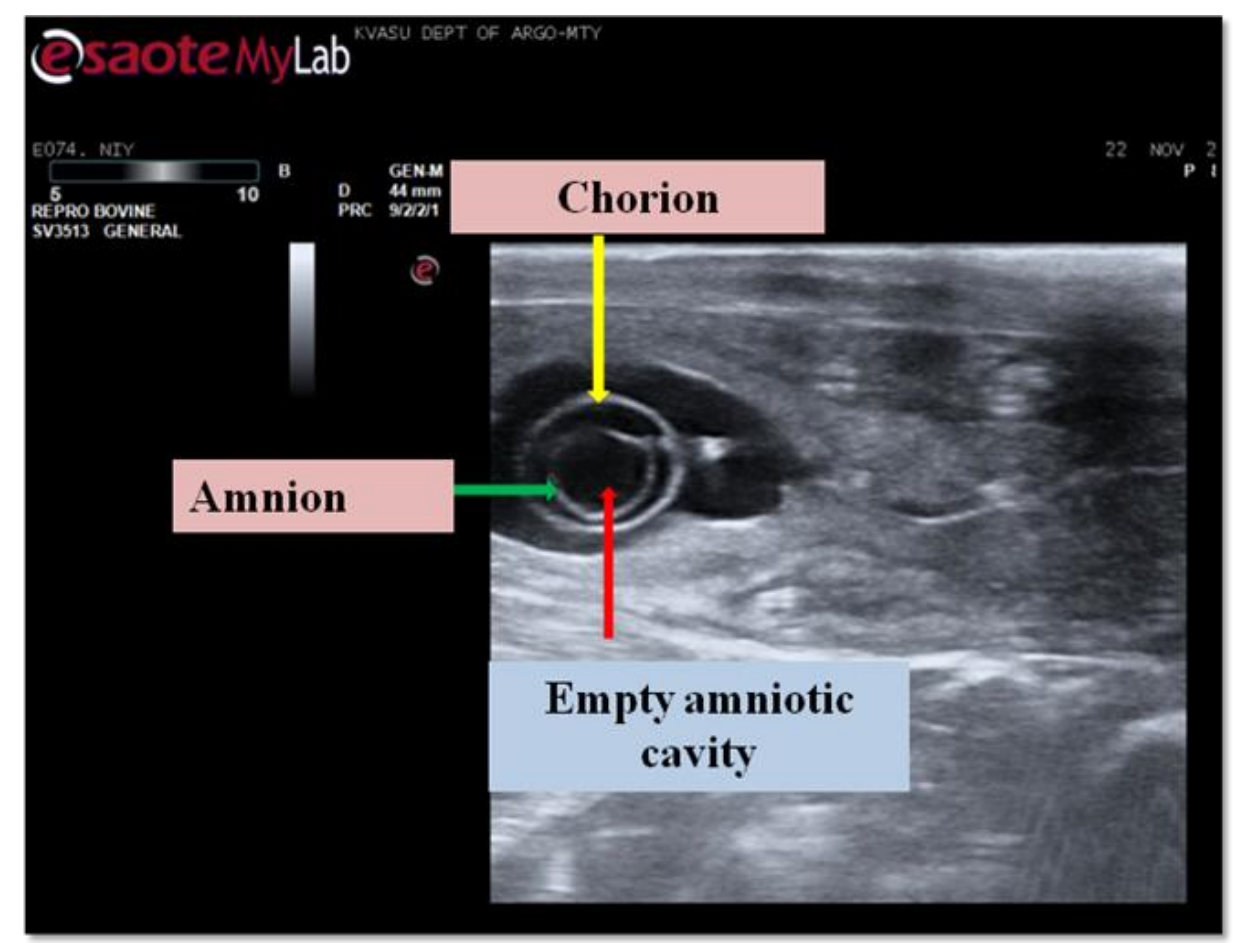

Fig.7 Ultrasonographic image of gravid horn on day45 post AI revealing less fluid accumulation in the gravid horn, abnormal thickening of the foetal membranes and no viable embryo within the amniotic cavity

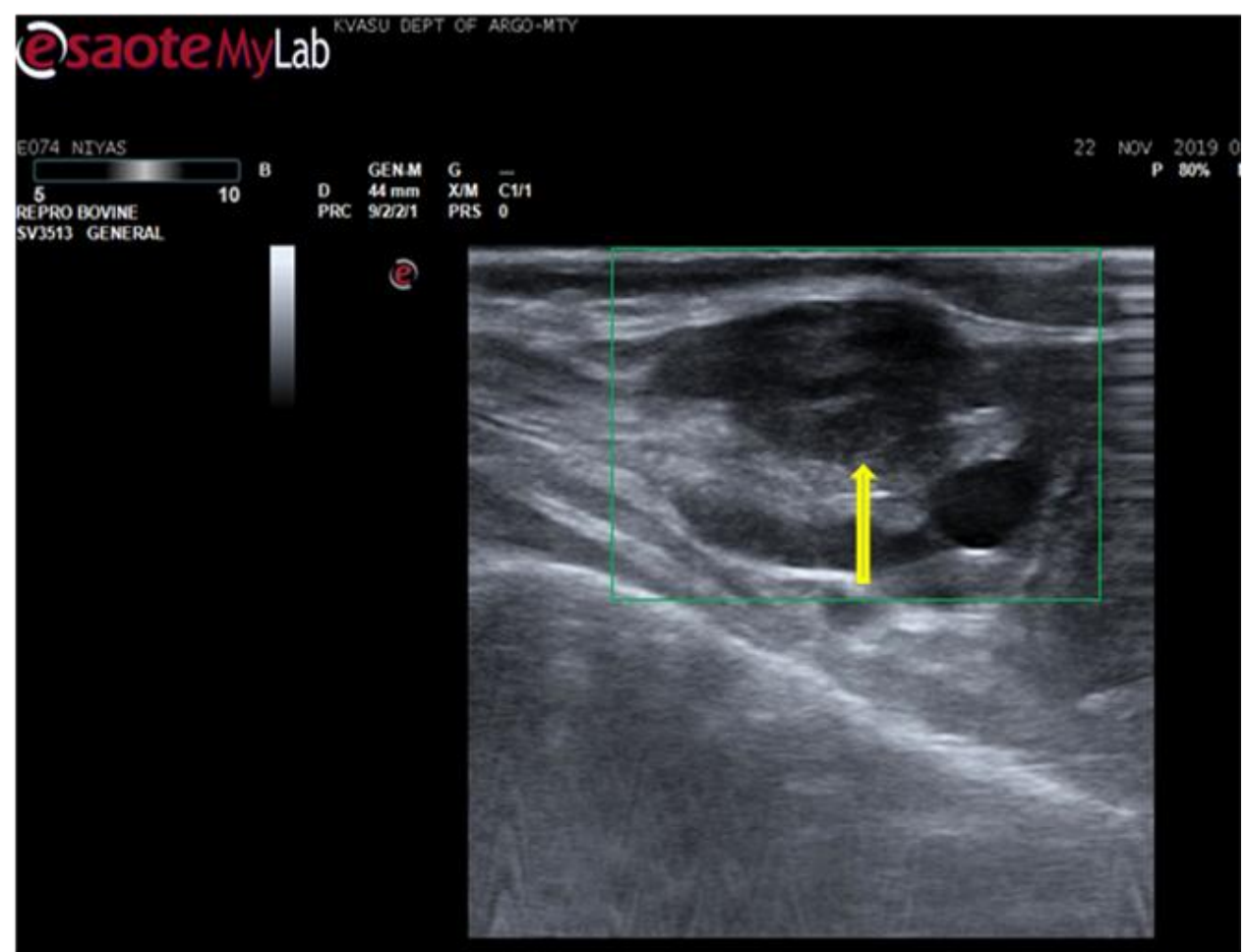

Fig.8 Luteal regression was completed by day 49: reduction in size and complete cessation of blood flow 


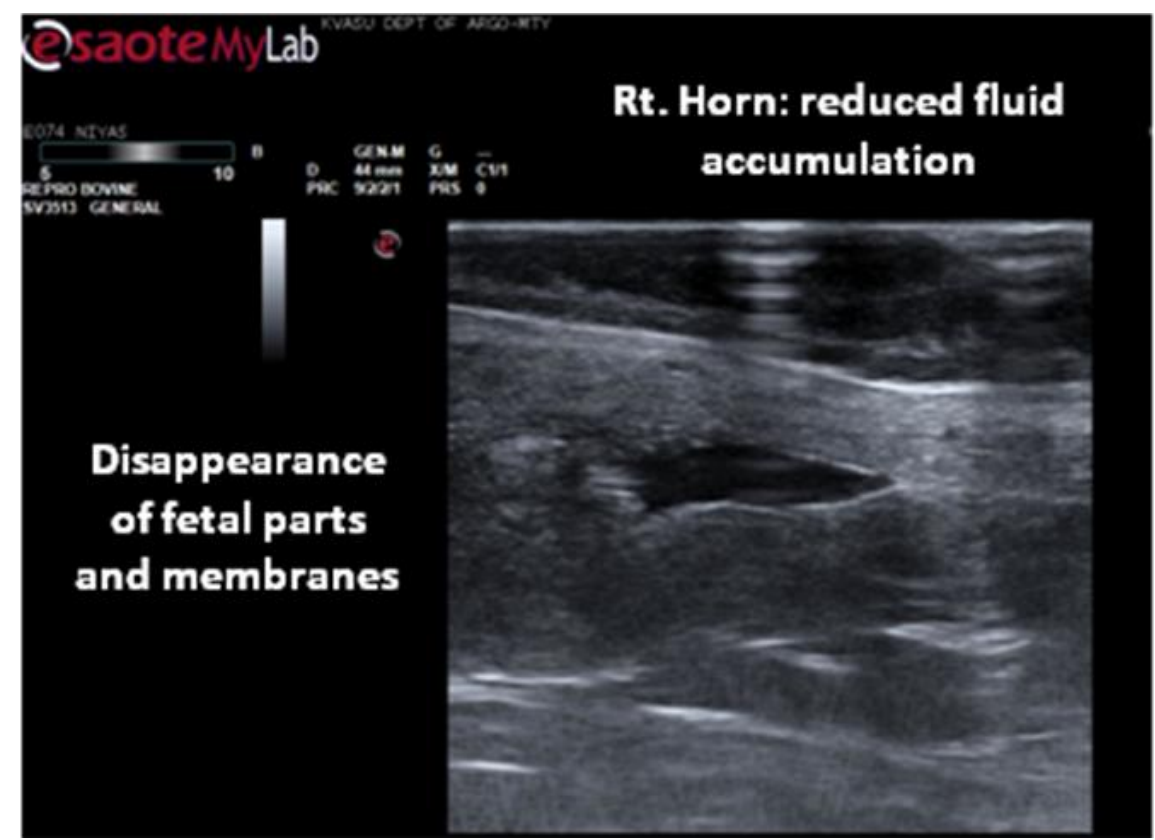

Fig.9 Reduced fluid accumulation in gravid horn and disappearance of embryonic debris

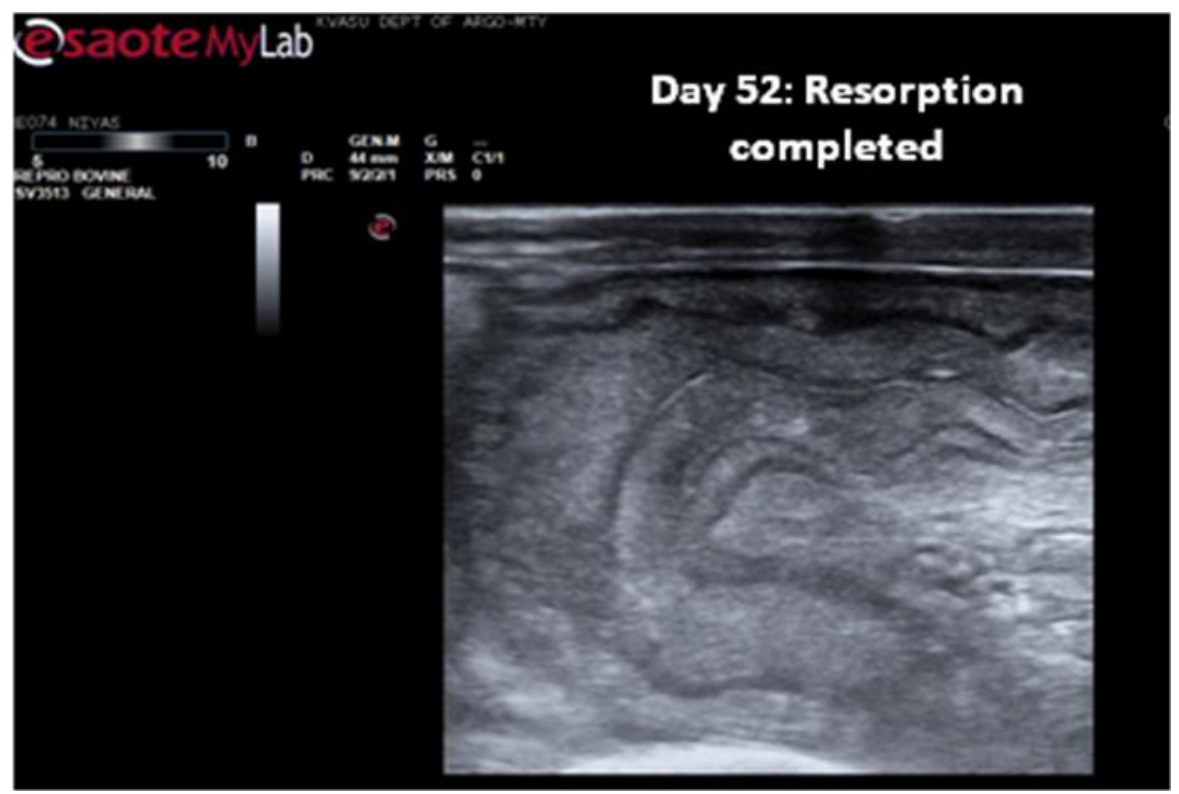

Fig.10 Complete disappearance of uterine fluid and embryo debris

Incidence of embryonic mortality between days 28 and 45 post breeding in the current investigation using transrectal ultrasonography was estimated as 4.12 per cent. Among the non-return cows 16.85 per cent $(n=61 / 362)$ had shown prolonged interoestrus interval ( $>24$ days as against the normal cycle length of 18-24 days) which could be attributed to EED. The early pregnancy diagnosis carried out by TRUS on day 28 post-insemination, should be reevaluated for diagnosis of embryonic mortality on day 45 post-insemination as well.

\section{Acknowledgement}

The authors are thankful to The Professor \& Head, University Livestock Farm \& Fodder 
Research Development Scheme and The Dean, College of veterinary and animal sciences, Mannuthy, Kerala for allowing the facilities of the institution for conducting this research work.

\section{References}

Awasthi, M.K., Khare, A., Kavani, F.S., Siddiquee, G.M. and Dhami, A.J.2011. Early pregnancy diagnosis in water buffaloes using trans-rectal utrasonography. IndianJ. Anim. Reprod., 32(1): 47-79.

Bajaj, N.K. and Sharma, N.2011. Endocrine causes of early embryonic death: an overview. Curr. Res. Dairy Sci., 3 (1): $1-24$.

Bajaj. N.K. (2001). Effects of herbal medication on endometritis in buffaloes. M.Sc. Thesis, Gujarat Agriculture University, Anand Campus, S.K. Nagar (Gujarat), India.

Balhara, A.K., Gupta, M., Singh, S., Mohanty, A.K. and Singh, I., 2013. Early pregnancy diagnosis in bovines: current status and future directions. The Scientific World Journal, 2013: 1-10.

Ball, P.J.H. and Logue, D.D.N.1994. Ultrasound diagnosis of pregnancy in cattle. Vet. Rec., 134: 532.

Beal, W.E., Perry, R.C., Corah, L.R., 1992. The use of ultrasound in monitoring reproductive physiology of beef cattle. J. Anim. Sci. 70: 924-929.

Bekele, N., Addis, M., Abdela, N. and Ahmed, W.M., 2016. Pregnancy diagnosis in cattle for fertility management: a review. Global Veterinaria, 16(4): 355-364.

Bhoraniya, H.L., Dhami, A.J., Naikoo, M. and Divekar, B.S. 2011. Early pregnancy diagnosis through transrectal ultrasonography and plasma progesterone assay in Kankrej cows. Indian J. Anim. Reprod., 32(2): 23-26.
Chaudhary, A.K. and Purohit, G.N., 2012. Ultrasonographic detection of early pregnancy loss in dairy cows. J. Anim. Sci. Adv, 2(8): 706-710.

Diskin, M.G. and Morris, D.G., 2008. Embryonic and early foetal losses in cattle and other ruminants. Reproduction in Domestic Animals, 43: 260-267.

Edmonson, A.J., Lean, I.J., Weaver, L.D., Farver, T. and Webster, G., 1989. A body condition scoring chart for Holstein dairy cows. Journal of dairy science, 72(1): 68-78.

Fricke, P.M. 2002. Scanning the future: Ultrasonography as a reproductive management tool for dairy cattle. J. Dairy Sci., 85(8): 1918-1926.

Grimard, B., Freret, S., Chevallier, A., Pinto, A., Ponsart, C., and Humblot, P. 2006. Genetic and environmental factors influencing first service conception rate and late embryonic/foetal mortality in low fertility dairy herds. Anim. Reprod. Sci., 91: 31-44.

Hadiya, K.K., Dhami, A.J., Nakrani, B.B., Patel, J.A. and Sarvaiya, N.P. 2015. Predictive efficiency of USG and plasma progesterone assay for detection of early pregnancy and embryonic mortality in cattle. G.J.B.B., 4(1): 277281.

Kastelic, J.P., Curran, S., Pierson, R.A. and Ginther, O.J. 1988. Ultrasonic evaluation of the bovine conceptus. Theriogenology. 29(1): 39-54.

Kastelic, J.P., Curran, S., Pierson, R.A. and Ginther, O.J. 1988. Ultrasonic evaluation of the bovine conceptus. Theriogenology. 29(1): 39-54.

Kastelic, J.P., Northey, D.L. and Ginther, O.J., 1991. Spontaneous embryonic death on days 20 to 40 in heifers. Theriogenology, 35(2): 351363.

Noakes, D.E., Parkinson, T.J. and England, 
G.C.W. 2009.Veterinary reproduction and obstetrics. $\left(9^{\text {th }}\right.$ Ed.).Saunders, $950 \mathrm{p}$.

Patel, J.A., Kavani, F.S., Derashri, H.J. and Sarvaiya, N.P. 2005. Use of ultrasonography in detection of early pregnancy and embryonic mortality in Holstein Friesian cow. Indian J. Dairy Sci., 58(5): 352-355.

Pieterse, M.C., Szenci, O., Willemse, A.H., Bajcsy, C.S.A., Dieleman, S.J. and Taverne, M.A.M. 1990. Early pregnancy diagnosis in cattle by means of linear array real-time ultrasound scanning of uterus and a qualitative and quantitative milk progesterone test. Theriogenology. 33: 697-707.

Pinki Rani, R.K. Chandolia, Ravi Dutt, Nitin Soni, S.S. Dhaka, Sandeep Kumar, A.K. Pandey and Gyan Singh. 2018. Ultrasonographic Assessment of Embryonic Mortality in Cows. Int.J.Curr.Microbiol.App.Sci. $\quad 7(06)$ : 387-399.

Prvanovic, N., Tomaskovis, A., Grizelj, J. and Kocila, M.S.P., 2009. Monitoring of early pregnancy and early embryonic mortality by ultrasound and determination of PAG and progesterone in cows. Veterinarskiarhiv, 79(3), p.259.
Romano, J.E., Thompson, J.A. and Kraemer, D.C. 2006. Early Pregnancy Diagnosis by trans-rectal ultrasonography in dairy cattle. Theriogenology. 66(4): 10341041.

Santos, J.E.P., Thatcher, W.W., Chebel, R.C., Cerri, R.L.A. and Galvao, K.N. 2004. Effect of embryonic death rates in cattle on efficacy of estrus synchronization programme. Anim. Reprod. Sci., 82: 513-535.

Silke, V., Diskin, M.G., Kenny, D.A., Boland, M.P., Dillon, P., Mee, J.F. and Sreenan, J.M. 2002. Extent, pattern and factors associated with late embryonic loss in dairy cows. Anim. Reprod. Sci., 71: 112.

Stronge, A.J.H., Sreenan, J.M., Diskin, M.G., Mee, J.F., Kenny, D.A and Moris, D.G. 2005. Post-insemination milk progesterone concentration and embryo survival in dairy cows. Theriogenology, 64: 1212-1224.

Szenci, O., Varga, J. and Bajcsy, A.C. 1998. Role of early pregnancy diagnosis by means of ultrasonography in improving reproductive efficiency in a dairy herd: a retrospective study. Bovine Practitioner, 32(2): 67-69.

\section{How to cite this article:}

Niyas. E., Shibu Simon, Reni John, Ani S. Das, D. S. Suprith, S. Reshma and Anugraha Mercy Easaw. 2020. Ultrasonographic Assessment of Embryonic Loss between Days 28 And 45 Post Insemination in Crossbred Dairy Cattle of Kerala. Int.J.Curr.Microbiol.App.Sci. 9(05): 328339. doi: https://doi.org/10.20546/ijcmas.2020.905.036 